\title{
Assessment of Endotracheal Tube Position After Oral Intubation in Neonates
}

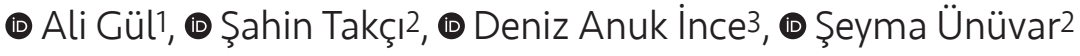 \\ ${ }^{1}$ Gaziosmanpaşa University Faculty of Medicine, Department of Pediatrics, Tokat, Turkey \\ ${ }^{2}$ Gaziosmanpaşa University Faculty of Medicine, Department of Pediatrics, Division of Neonatology, Tokat, Turkey \\ ${ }^{3}$ Başkent University Faculty of Medicine, Department of Pediatrics, Division of Neonatology, Ankara, Turkey
}

\begin{abstract}
Aim: Endotracheal intubation is a common procedure in the delivery room and neonatal intensive care unit. We aimed to determine the accuracy of this method of endotracheal tube (ETT) placement in our neonatal cohort.

Materials and Methods: Data on infants requiring oral intubation were reviewed retrospectively. The initial ETT depth of insertion had been calculated using the Tochen 7-8-9 rule. The initial depth was compared to the mid-tracheal region. The differences between the initial and ideal depth was calculated and divided by the mid-tracheal distance. Infants were grouped according to their weights as $\leq 1000 \mathrm{~g}, 1001$ to $2000 \mathrm{~g}, 2001$ to $3000 \mathrm{~g}$ and $\geq 3001$ g.

Results: We evaluated ETT placement in 160 neonates. The mean gestational age was $32.2 \pm 4.4$ weeks (23 to 41 weeks) and the mean weight was $1989 \pm 829 \mathrm{~g}$ (560 to $3800 \mathrm{~g}$ ). The mean range of the difference between the initial depth and ideal depth divided by mid-tracheal distance was $0.39 \pm 0.04,0.35 \pm 0.04,0.46 \pm 0.05$, and $0.23 \pm 0.04$ in infants weighing $\leq 1000 \mathrm{~g}, 1001$ to $2000 \mathrm{~g}, 2001$ to $3000 \mathrm{~g}$ and $\geq 3001 \mathrm{~g}$ respectively ( $\mathrm{p}=0.025$ ). The differences between the 2001-3000 g group and the 1001-2000, also the 2001-3000 g group and the $\geq 3001 \mathrm{~g}$ group were statistically significant $(p<0.05)$.

Conclusion: The 7-8-9 rule should be used to assess ETT length in neonates, especially in those weighing more than $3 \mathrm{~kg}$. As this rule has low accuracy for extremely low birth weight neonates, its reliability may not be high for neonates weighing less than $3 \mathrm{~kg}$ in weight.

Keywords: Endotracheal intubation, neonates, Tochen's rule, resuscitation, position of the tube
\end{abstract}

\section{Introduction}

Respiratory problems requiring endotracheal intubation are common during the neonatal period and occur extensively in neonatal practice. Endotracheal intubation is a common procedure in the delivery room and neonatal intensive care unit $(1,2)$. As the tube malposition is associated with hypoxemia, pneumothorax, right upper lobe collapse and death, rapid confirmation of proper tube placement is critical (3). The correct position of the endotracheal tube
(ETT) tip is the mid-tracheal area. However, the success rate of correct ETT placement for junior medical staff is less than $50 \%$, and accidental esophageal intubation is common (4). The incidence of malposition for the placement of ETT can be as high as 50\% (5). Pediatric resident trainees are currently not provided with adequate guidance to ensure the development of competency in neonatal intubation (4). Proficiency at intubation in controlled circumstances requires 40 or more procedures (6). Previously, the 7-8-9 rule was described by Tochen (7) and recommended by 
the American Academy of Pediatrics (2) to determine the depth of ETT insertion. Although this rule is frequently used in neonatal practice, studies about its accuracy are inadequate. Using gestational age can be useful especially when infants are intubated in the delivery room. Despite this, although gestation information is usually both accurate and available, the baby will not have been weighed (8). X-ray chest radiography is the gold standard procedure available to determine the tube position; however, this is often delayed until after ventilation has initiated. Therefore, a number of rapid point-of-care methods (e.g., clinical signs, exhaled carbon dioxide $\left(\mathrm{CO}_{2}\right)$ detectors, respiratory function monitors and ultrasound) to confirm the correct tube placement have been developed (3). Nasal-tragus length (NTL) to predict the optimal ETT depth with the formula, NTL plus $1 \mathrm{~cm}$, has been suggested as clinically practical for newborn infants (9). In our country, NTL is currently used under the Neonatal Resuscitation Program (NRP) recommendations (10). Foot length has been suggested as a reliable and reproducible predictor of nasotracheal tube length (11). Clinical findings of accurate tube placement include an increase in heart rate, adequate chest wall movements, auscultation of breathing sounds in the axillary and an absence of sounds in the epigastric region (12). We conducted this study between 2013 and 2014, the period before the introduction of the NTL in the NRP guidelines in Turkey. We aimed to determine the accuracy of this method in the prediction of the optimal ETT depth in our neonatal cohort. Hence, we might contribute to studies on the estimation of accurate ETT depth.

\section{Materials and Methods}

The data of infants requiring oral intubation from March 2013 to December 2014 were reviewed retrospectively. The subjects' demographic and clinical data were collected retrospectively from hospital records. Infants with congenital anomalies that complicated the intubation procedure were excluded. The intubation had been performed by a supervised pediatric resident or a neonatologist in accordance with guidelines. The initial ETT depth of insertion had been calculated using actual weight with the 7-8-9 rule. After endotracheal intubation, the positioning of the tube was confirmed by observing symmetrical chest-wall motion and listening for equal breath sounds in the chest and additional corrections were performed. While a position between T1 and $\mathrm{T} 2$ represented an acceptable standard for the position of the ETT tip on chest radiographs (11), the mid-tracheal position was defined also as the point halfway between the inferior clavicle and carina on a chest radiograph (13). The initial depth was compared to the ideal depth (mid-tracheal region). These measurements were taken on the chest $X$-rays by a researcher of the present study (S..T.). The differences

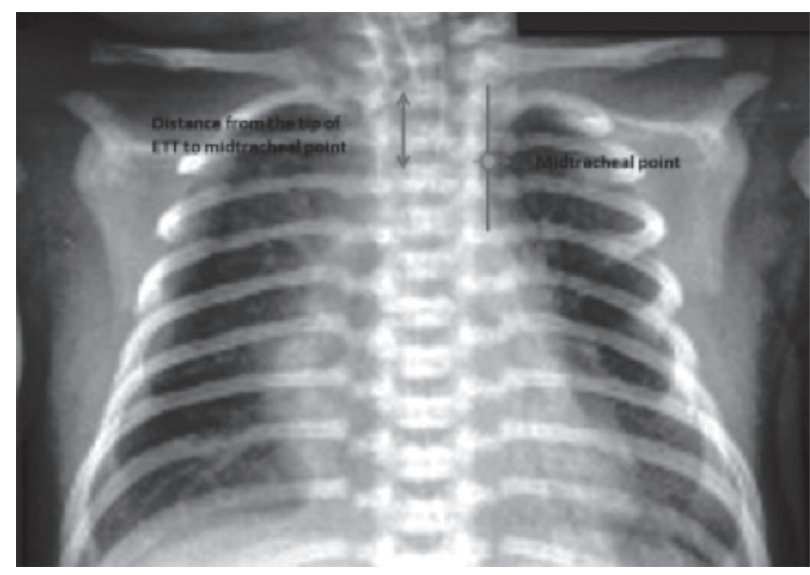

Figure 1. Assessment of the mid-tracheal point and the distance from the tip of the endotracheal tube to the mid-tracheal point ETT: Endotracheal tube

between the initial and ideal depth were calculated and divided by the mid-tracheal distance. The assessment of the mid-tracheal point and the distance from the tip of the ETT to the mid-tracheal point is illustrated in Figure 1. The ideal proportion was zero according to this calculation. The formula is: (initial depth minus ideal depth)/mid-tracheal distance (note: ideal depth is defined as the mid-tracheal point and so equals the mid-tracheal distance). The neonate's heads were placed in a neutral position (i.e., neck neither flexed nor extended) during the chest X-ray examinations according to the protocol of the neonatal intensive care unit (NICU). Only the first accurate chest radiographs were taken into account. Infants were placed into weight groups of 1000 g or less, 1001 to 2000 g, 2001 to 3000 g, and more than 3000 g. These groups were chosen based on the weight categories used to enable the appropriate selection of ETT size. Data concerning demographic variables, intubation time and intubation place were collected. Because of the retrospective nature of this study, it is outside the scope of the ethics committee, and so we did not apply to ethics committee. In addition to that, we did not disclose any patient information in accordance with the Helsinki declaration.

\section{Statistical Analysis}

Data were obtained regarding the arithmetic mean and standard deviation. Independent Samples-t or ANOVA tests were used to compare the variables between groups. A $p$ value $<0.05$ was considered significant. Analyses were performed using SPSS 19 (IBM SPSS Statistics 19, SPSS inc., an IBM Co., Somers, NY).

\section{Results}

This retrospective cohort study evaluated ETT placement in 160 neonates. The mean gestational age was $32.2 \pm 4.4$ weeks ( 23 to 41 weeks) and the mean weight was $1989 \pm 829 \mathrm{~g}$ (560 to 
$3800 \mathrm{~g})$. Seventeen (10.6\%) infants weighed $1000 \mathrm{~g}$ or less, 70 (43.7\%) weighed between 1001 and $2000 \mathrm{~g}, 50$ (31.3\%) infants weighed between 2001 and $3000 \mathrm{~g}$ and 23 infants (14.4\%) weighed $3001 \mathrm{~g}$ or above. Table I shows the demographic and clinical data of the subjects with the distance of the ETT tip to the mid-tracheal point. The ETT tip was lower than the ideal depth in 51 (31.9\%) infants and it was higher in 109 (68.1\%) infants. Right bronchus intubation was detected in 23 (14.4\%) infants. The mean range of the difference between the initial depth and ideal depth divided by mid-tracheal distance was $0.39 \pm 0.17,0.35 \pm 0.30,0.46 \pm 0.38$, and $0.23 \pm 0.19$ in infants weighing $1000 \mathrm{~g}$ or less, 1001 to $2000 \mathrm{~g}$, 2001 to $3000 \mathrm{~g}$, and $3001 \mathrm{~g}$ or above respectively $(\mathrm{p}<0.05)$. The difference between the 2001-3000 g group and the over $3000 \mathrm{~g}$ group was statistically significant. Table II shows the values of the ratio in all study groups. The number of infants intubated above the ideal depth was more than twice of the number of infants intubated below the ideal depth (109 infants vs

Table I. Demographic and clinical data of subjects with distance of endotracheal tube tip to mid-tracheal point

\begin{tabular}{|c|c|c|c|c|}
\hline \multirow{2}{*}{\multicolumn{2}{|c|}{ Variables }} & \multicolumn{2}{|c|}{$\begin{array}{l}\text { Distance of ETT } \\
\text { tip to } \\
\text { mid-tracheal point } \\
\text { (cm) }\end{array}$} & \multirow[t]{2}{*}{$\begin{array}{l}\mathrm{p} \\
\text { value }\end{array}$} \\
\hline & & \multirow{2}{*}{\begin{tabular}{|l|}
$\mathbf{n}(\%)$ \\
$89(55.6)$
\end{tabular}} & \multirow{2}{*}{$\begin{array}{l}\text { Mean } \pm \\
\text { SEM } \\
-2.05 \pm 0.86\end{array}$} & \\
\hline Gender & Male & & & - \\
\hline & Female & $71(44.4)$ & $-3.03 \pm 0.8$ & \\
\hline \multirow[t]{4}{*}{$\begin{array}{l}\text { Radiography } \\
\text { time }\end{array}$} & $\begin{array}{l}\text { First } 30 \\
\text { minutes }\end{array}$ & $72(45.0)$ & $-1.35 \pm 0.69$ & \multirow{4}{*}{0.297} \\
\hline & $\begin{array}{l}30 \text { minutes to } 2 \\
\text { hours }\end{array}$ & $52(32.5)$ & $-3.71 \pm 1.16$ & \\
\hline & 2 to 24 hours & $34(21.3)$ & $-3.2 \pm 1.57$ & \\
\hline & After first day & $2(1.3)$ & $0.7 \pm 1.6$ & \\
\hline \multirow{3}{*}{$\begin{array}{l}\text { Place of } \\
\text { intubation }\end{array}$} & Delivery room & $31(19.4)$ & $-0.91 \pm 1.01$ & \multirow{3}{*}{0.265} \\
\hline & NICU & $97(60.6)$ & $-2.7 \pm 0.75$ & \\
\hline & $\begin{array}{l}\text { Out of the } \\
\text { center }\end{array}$ & $32(20.0)$ & $-3.36 \pm 1.63$ & \\
\hline \multirow[t]{4}{*}{ Birth weight } & $1000 \mathrm{~g}$ or less ${ }^{\mathrm{ab}}$ & $17(10.6)$ & $-1.31 \pm 1.35$ & \multirow{4}{*}{0.002} \\
\hline & 1001 to $2000 \mathrm{~g}^{\mathrm{a}}$ & $70(43.8)$ & $-2.61 \pm 0.74$ & \\
\hline & 2001 to $3000 \mathrm{~g}^{\mathrm{b}}$ & $50(31.3)$ & $-3.74 \pm 1.4$ & \\
\hline & $\geq 3001 \mathrm{~g}^{\mathrm{a}}$ & $23(14.4)$ & $-0.24 \pm 1.24$ & \\
\hline \multirow{2}{*}{$\begin{array}{l}\text { Right main } \\
\text { bronchus } \\
\text { intubation }\end{array}$} & No & $121(75.6)$ & $-5.1 \pm 0.57$ & \multirow[t]{2}{*}{-} \\
\hline & Yes & $39(24.4)$ & $5.63 \pm 0.76$ & \\
\hline
\end{tabular}

ETT: Endotracheal tube, SEM: Standard error of mean, aba,b: Same uppercase letters indicate insignificant difference within the same column $(p<0.05)$, NICU: Neonatal intensive care unit
51 infants). There were no statistically significant difference between birth weight groups and location of ETT in terms of being below or above the ideal depth (Table III).

\section{Discussion}

There have been various studies to evaluate both the correctness and usefulness of different techniques for ETT placement in neonates. Although one study found flexible fiberoptic bronchoscopy to correlate well with chest radiography (14), another study without chest radiography, concluded that a mathematical algorithm could be used to estimate the depth of ETT insertion and so could help a practitioner perform intubation when radiography is not available (15). All these attempts are to overcome both ETT malposition and its associated complications, while also allowing for rapidly deciding the appropriate ETT insertion length for resuscitation. Despite these techniques and methods, until recently, the Tochen rule was used in neonatal resuscitation practices for assessing depth of ETT insertion. This rule was accepted as useful, safe and effective by some authors (13). In our country, The Tochen rule has not been used since 2015. NTL is in use in accordance with current NRP

\begin{tabular}{|c|c|c|c|c|}
\hline \multicolumn{2}{|l|}{ Variables } & \multicolumn{2}{|c|}{ (ID-MTD)/MTD* ratio } & \multirow{2}{*}{$\begin{array}{l}\mathrm{P} \\
\text { value }\end{array}$} \\
\hline & & \multirow{2}{*}{$\begin{array}{l}\text { n (\%) } \\
89\end{array}$} & \multirow{2}{*}{$\begin{array}{l}\text { Mean } \pm \\
\text { SEM }\end{array}$} & \\
\hline Gender & Male & & & - \\
\hline & Female & 71 & $0.36 \pm 0.04$ & \\
\hline \multirow{3}{*}{$\begin{array}{l}\text { Place of } \\
\text { intubation }\end{array}$} & Delivery room & 31 & $0.35 \pm 0.04$ & \multirow{3}{*}{$0.281^{* *}$} \\
\hline & $\mathrm{NICU}$ & 97 & $0.35 \pm 0.03$ & \\
\hline & $\begin{array}{l}\text { Out of the } \\
\text { center }\end{array}$ & 32 & $0.45 \pm 0.07$ & \\
\hline \multirow[t]{4}{*}{ Birth weight } & $1000 \mathrm{~g}$ or less ${ }^{\mathrm{ab}}$ & 17 & $0.39 \pm 0.04$ & \multirow{4}{*}{0.025} \\
\hline & 1001 to $2000 \mathrm{~g}^{\mathrm{a}}$ & 70 & $0.35 \pm 0.04$ & \\
\hline & 2001 to $3000 g^{b}$ & 50 & $0.46 \pm 0.05$ & \\
\hline & $\geq 3001 \mathrm{~g}^{\mathrm{a}}$ & 23 & $0.23 \pm 0.04$ & \\
\hline \multirow{2}{*}{$\begin{array}{l}\text { Location of } \\
\text { ETT }\end{array}$} & Below & 51 & $0.31 \pm 0.02$ & \multirow{2}{*}{$0.085^{*}$} \\
\hline & Above & 109 & $0.4 \pm 0.03$ & \\
\hline \multirow{2}{*}{$\begin{array}{l}\text { Right main } \\
\text { bronchus } \\
\text { intubation }\end{array}$} & No & 121 & $0.31 \pm 0.02$ & \multirow{2}{*}{$0.841^{*}$} \\
\hline & Yes & 39 & $0.4 \pm 0.03$ & \\
\hline \multirow[t]{2}{*}{ Prognosis } & Discharged & 123 & $0.37 \pm 0.03$ & \multirow{2}{*}{$0.159^{*}$} \\
\hline & Death & 37 & $0.36 \pm 0.03$ & \\
\hline
\end{tabular}

ETT: Endotracheal tube, SEM: Standard error of mean, ${ }^{*}$ : Independent Samples t-test was used (Initial depth-mid-tracheal distance)/mid-tracheal distance, **: ANOVA test was used, aba,ab: Same uppercase letters indicate insignificant difference within the same column $(\mathrm{p}<0.05)$, NICU: Neonatal intensive care unit, MTD: Monthly tax deduction, ID: Identy 
Table III. Birth weight groups distribution according to location of endotracheal tube for the ideal depth

\begin{tabular}{|l|l|l|l|l|}
\hline \multirow{2}{*}{$\begin{array}{l}\text { Birth weight } \\
\text { group }\end{array}$} & \multicolumn{2}{|l|}{ Location of ETT } & \multirow{2}{*}{ Total } & \multirow{2}{*}{ p value } \\
\cline { 2 - 4 } & $\begin{array}{l}\text { Above } \\
\mathbf{n}(\%)\end{array}$ & $\begin{array}{l}\text { Below } \\
\mathbf{n}(\%)\end{array}$ & & \\
\hline 1000 g or less & $5(29.4)$ & $12(70.6)$ & $17(100)$ & \multirow{2}{*}{0.442} \\
\hline 1001 to $2000 \mathrm{~g}$ & $18(25.7)$ & $52(74.3)$ & $70(100)$ & \\
\hline 2001 to $3000 \mathrm{~g}$ & $19(38)$ & $31(62)$ & $50(100)$ & \\
\hline$\geq 3001 \mathrm{~g}$ & $9(39.1)$ & $14(60.9)$ & $23(100)$ & \\
\hline Total & $51(31.9)$ & $109(68.1)$ & $160(100.0)$ & \\
\hline
\end{tabular}

ETT: Endotracheal tube, pearson chi-square test was used

guidelines (16). The present study determined that the depths of the ETT in neonates weighing more than $3000 \mathrm{~g}$ were more close to the ideal and more accurately inserted than those in 2001 to 3000 g neonates. Peterson et al. (13) reported that although this rule is sufficient to ensure accurate tube position in infants over $750 \mathrm{~g}$ body weight, it may lead to overestimation of the intubation depth for infants less than 750 g. In line with this view, Amarilyo et al. (17) reported that the application of Tochen's rule in extremely low birth weight infants led to inadequate tube placement in almost half the infants. The present study was consistent with these reports since the 7-8-9 rule was accurate and gave correct figures for ideal depth of insertion length of ETT for infants above $3000 \mathrm{~g}$. While the ratio of the depth of ETT insertion length in infants of less than $1001 \mathrm{~g}$ was higher than in infants of above $3000 \mathrm{~g}$, the difference was not statistically significant. This statistical insignificance might be due to the low number of infants weighing less than $1001 \mathrm{~g}$. Additionally, infants of less than $1001 \mathrm{~g}$ had been intubated by expert neonatology staff rather than by pediatrician residents. The decreased exposure of endotracheal intubation during both residency and fellowship training is a major concern $(4,18)$. Leone et al. (4) reported that the average number of intubation attempts per resident during training decreased from 38 to 12 during an eight year period. Also, noninvasive respiratory support methods may reduce the number of intubation attempts (19). There are a few limitations of the present study. Due to a disparity between the practitioners, the accuracy of ETT intubation may be influenced by the skill of practitioners. Another limitation of this study is that because of the retrospective nature of this study, the fact that we do not know how the infant's weight was estimated or obtained in order to decide on the insertion length of ETT. Weight is often not known at the time of intubation at birth and a rough prediction is used to determine the depth of the ETT insertion. Hence, that is a major disadvantage for this method. At the same time, infants of body weight between 2001 and $3000 \mathrm{~g}$ had a higher ratio of the depth of ETT insertion length than other infant groups. There is no conclusive explanation for this discrepancy, it might be because the intubations were done by different practitioners. When the intubation in neonates are done in an urgent or emergency situation in the $\mathrm{NICU}$ or delivery room, it should be performed in the shortest amount of time possible. Therefore, because determining or estimating the weight of the infant may be impossible or at least not accurate, the 7-8-9 rule has been unreliable in determining the ETT length in neonates requiring intubation $(13,20)$. Trained NICU personnel have also been shown to make errors of $22 \%$ to $33.6 \%$ in weight estimations (21). In addition, it has been suggested that the ETT depth may also be affected by the head position on the chest radiography, some methods have been proposed for correcting this (15). Guidance using the gestational age may be particularly useful in the delivery room, where the gestational age is usually accurate but the newborns have not been weighed yet (8). Kempley et al. (20) determined that the ETT length in neonates was related to gestation in a linear manner, an inconsistency with Tochen's rule, but the relationship with weight was non-linear. Other methods are based on physical markers like NTL, sternal length or head circumference. These may be faster and more accurate to assess the depth of ETT in neonates $(9,22)$. Because the malposition of the ETT can cause serious complications, the rapid determination of tube placement is a very important goal. For this purpose, however, the gold standard method is currently chest radiography. Despite this, various new techniques have been suggested, e.g., measuring air going in and out of the lung (using a respiratory function monitor) (23), measuring the amount of exhaled $\mathrm{CO}_{2}(1,24)$, and using ultrasound to image the tube within the windpipe (3). The purpose of this study was to verify our clinical experience and its agreement with the currently available reference values. We believe that these efforts will provide objective and scientific information for the optimal resuscitation of neonates.

\section{Study Limitations}

There are a few limitations of the present study. Because of the disparity between the practitioners, the accuracy of ETT intubation may be influenced by the skill of practitioners. Another limitation of this study is, because of the retrospectively nature of this study, we do not know how the infant's weight was estimated or obtained to decide the insertion length of ETT.

\section{Conclusion}

Based on this study, in neonates who need intubation, particularly for those over $3 \mathrm{~kg}$, the 7-8-9 rule can be used to determine ETT length. Although this rule has been implemented for many years, as it is open to practitioner differences, especially in weight estimation, its accuracy and sensitivity are unclear in newborns less than $3 \mathrm{~kg}$ in weight. 
Otherwise, the expertise of the practitioners may affect the accuracy of the ETT location.

\section{Ethics \\ Ethics Committee Approval: Retrospective study. Informed Consent: Not applicable. \\ Peer-review: External and internal peer-reviewed.}

\section{Authorship Contributions}

Surgical and Medical Practices: Ş.T., D.A.I., Concept: A.G., Ş.T., D.A.I., Design: Ş.T., A.G., Data Collection and Processing: Ş.Ü., Ş.T., A.G., Analysis and Interpretation: Ş.T., A.G., Literature Search: Ş.T., A.G., Writing: A.G.

Conflict of Interest: No conflict of interest was declared by the authors.

Financial Disclosure: The authors declared that this study received no financial support.

\section{References}

1. O'Donnell CP, Kamlin CO, Davis PG, Morley C). Endotracheal intubation attempts during neonatal resuscitation: success rates, duration, and adverse effects. Pediatrics 2006;117:16-21.

2. Niermeyer S, Kattwinkel J, Van Reempts P, et al. International Guidelines for Neonatal Resuscitation: An excerpt from the Guidelines 2000 for Cardiopulmonary Resuscitation and Emergency Cardiovascular Care: International Consensus on Science. Contributors and Reviewers for the Neonatal Resuscitation Guidelines. Pediatrics 2000;106:E29.

3. Schmölzer GM, Roehr CC. Techniques to ascertain correct endotracheal tube placement in neonates. Cochrane Libr 2014.

4. Leone TA, Rich W, Finer NN. Neonatal intubation: success of pediatric trainees. I Pediatr 2005;146:638-41.

5. McMillan DD, Rademaker AW, Buchan KA, Reid A, Machin G, Sauve RS. Benefits of orotracheal and nasotracheal intubation in neonates requiring ventilatory assistance. Pediatrics 1986;77:3944.

6. Mulcaster JT, Mills I, Hung OR, et al. Laryngoscopic IntubationLearning and Performance. Anesthesiology 2003:98:23-7.

7. Tochen ML. Orotracheal intubation in the newborn infant: a method for determining depth of tube insertion. J Pediatr 1979:95:1050-1.

8. Mainie P, Carmichael A, McCullough S, Kempley S. Endotracheal tube position in neonates requiring emergency interhospital transfer. Am / Perinatol 2006;16:121-4.

9. Wang $\mathrm{TC}$, Kuo LL, Lee CY. Utilizing nasal-tragus length to estimate optimal endotracheal tube depth for neonates in Taiwan. Indian | Pediatr 2011;78:296-300.
10. Çoban A, Kırımi E, Kültürsaray $N$, et al. 5. Ders: Alternatif Havayolları: Endotrakeal tüp ve Laringeal maske İçinde: Çoban A, (ed). Yenidoğan Canlandırma Programı (NRP) Uygulayıc Eğitim Kurs Kitabı. Ankara, Turkey, TC Sağıık Bakanlığı, 2017;1921.

11. Embleton ND, Deshpande SA, Scott D, Wright C, Milligan DW. Foot length, an accurate predictor of nasotracheal tube length in neonates. Arch Dis Child Fetal Neonatal Ed 2001;85:60-4.

12. Kattwinkel J, Perlman JM, Aziz K, et al. Part 15: neonatal resuscitation 2010 american heart association guidelines for cardiopulmonary resuscitation and emergency cardiovascular care. Circulation 2010;122(18 Suppl 3):909-19.

13. Peterson J, Johnson N, Deakins K, Wilson-Costello D, Jelovsek J, Chatburn R. Accuracy of the 7-8-9 Rule for endotracheal tube placement in the neonate. I Perinatol. 2006;26:333-6.

14. Lee YS, Soong WJ, Jeng MJ, et al. Endotracheal Tube Position in Pediatrics and Neo ates: Comparison Between Flexible Fiberoptic Bronchoscopy and Chest Radiograph. Chi nese Med i cal Jour nal (Tai pei) 2002;65:341-4.

15. Lange $\mathbf{M}$, Jonat $\mathrm{S}$, Nikischin $\mathbf{W}$. Detection and correction of endotracheal-tube position in premature neonates. Pediatr Pulmonol 2002;34:455-61.

16. Çoban A, İnce Z, Kırımi E, et al. Yenidoğan Canlandırma Programı (NRP) Uygulayıcı Eğitim Kurs Kitabı. Ankara, Turkey, TC Sağıık Bakanlığı, 2017.

17. Amarilyo G, Mimouni FB, Oren A, Tsyrkin S, Mandel D. Orotracheal tube insertion in extremely low birth weight infants. J Pediatr 2009;154:764-5.

18. Falck AJ, Escobedo MB, Baillargeon JG, Villard LG, Gunkel $\mathrm{JH}$. Proficiency of pediatric residents in performing neonatal endotracheal intubation. Pediatrics 2003;112:1242-7.

19. Morley C), Davis PG, Doyle LW, et al. Nasal CPAP or intubation at birth for very preterm infants. N Engl I Med 2008;358:700-8.

20. Kempley ST, Moreiras JW, Petrone FL. Endotracheal tube length for neonatal intubation. Resuscitation 2008;77:369-73.

21. Lubitz DS, Seidel JS, Chameides L, Luten RC, Zaritsky AL, Campbell FW. A rapid method for estimating weight and resuscitation drug dosages from length in the pediatric age group. Ann Emerg Med 1988;17:576-81.

22. Shukla HK, Hendricks-Munoz KD, Atakent Y, Rapaport S. Rapid estimation of insertional length of endotracheal intubation in newborn infants. J Pediatr 1997;131:561-4.

23. Schmolzer GM, Kamlin OC, Dawson JA, te Pas AB, Morley C), Davis PG. Respiratory monitoring of neonatal resuscitation. Arch Dis Child Fetal Neonatal Ed 2010;95:295-303.

24. Aziz HF, Martin JB, Moore JJ. The pediatric disposable end-tidal carbon dioxide detector role in endotracheal intubation in newborns. J Perinatol 1999;19:110-3. 